\title{
MENINGKATKAN PROSES BELAJAR MENGAJAR DENGAN MENGGUNAKAN SISTEM E-LEARNING STUDI KASUS SMP NEGERI 24 PADANG
}

\author{
Yanti Yusman ${ }^{1}$
}

\begin{abstract}
There are some of students feel afraid to participate in learning, because there are some discussion or theme of learning is a problem that occurs in students of SMP Negeri 24 Padang Now this with Information and Communication Technology (ICT) learning process can be done through electronic media called e-learning. One way to use the right learning media so that students are more active to play a role in the learning process. As a medium that will be used by students and teachers then built Learning Management System with uses Analytic Network Process (ANP) method.
\end{abstract}

Keywords: E-learning, ANP method

\section{INTISARI}

Sebagian dari siswa merasa takut untuk berpartisifasi dalam belajar, karena ada beberapa pembahasan atau tema pembelajaran yang menjadi suatu permasalahan yang pada siswa SMP Negeri 24 Padang Sekarang ini dengan Information and Communication Technology (ICT), proses pembelajaran dapat dilakukan melalui media elektronik yang disebut e-learning. Salah satu cara dengan mengunakan media pembelajaran yang tepat agar siswa lebih aktif agar banyak berperan di dalam proses belajar. Sebagai media yang akan digunakan oleh siswa dan pengajar maka dibangunlah Learning Management System dengan mengunakan metode Analytic Network Process ( ANP).

Kata kunci: E-learning, Metode ANP 
${ }^{1}$ Dosen Universitas Pembangunan Panca Budi (UNPAB) Medan

PENDAHULUHAN

sudah baat ini konsep e-learning masyarakat dunia, terbukti dengan maraknya implementasi e-learning di lembaga pendidikan (sekolah, training dan universitas) maupun industri (Cisco System, IBM, HP, Oracle). Konsep yang kemudian terkenal dengan sebutan e-learning ini membawa pengaruh terjadinya proses transformasi pendidikan konvensional ke dalam bentuk digital, baik secara isi (content) dan sistemnya.

E-learning adalah sebuah proses pembelajaran salah satu media yang digunakan adalah jaringan komputer memungkinkan untuk dikembangkan proses belajar mengunakan web sehinga dapat dikembangkan kedalam jaringan komputer yang lebih luas yaitu internet. Sehingga sistem e-learning disebut juga internet enabled learning penyajian e-learning berbasis web ini lebih interaktif.

Pembelajaran merupakan kegiatan interaksi / belajar mengajar dari nara sumber atau guru dengan sipembelajar atau siswa, yang biasanya dilaksanakan dalam ruangan baik tertutup maupun terbuka. Pembelajaran yang terjadi sekarang ini di SMP Negeri 24 Padang masih bersifat klasikal, artinya setiap kegiatan belajar dan mengajar. Oleh sebab itu penulis akan membantu SMP Negeri 24 Padang.dalam mengembangkan sistem e-learning
PENDEKATAN

MASALAH

E-learning

jenis belajar mengajar yang memungkinkan tersampaikan bahan ajar ke siswa dengan mengunakan media internet atau media jaringan komputer lain ( Darin E. Hartley dalam Wahono : 2003 ).

E-Learning is the Use Of electronic tecnologies to create learning experiences yang artinya pemebelajaran yang dibuat secara lebih terbuka sehingga menyebabkan proses dengan cara untuk memformulasikan, mengorganisir dan membuat pengalaman belajar dapat dilakukan secara lebih luas ( Harton : 2012 ).

E-Learning berarti pemebelajaran dengan mengunakan jasa bantuan perangkat elektonika atau pembelajaran yang dalam pelaksanaanya didukung oleh jasa teknologi seperti telepon, audio, vidiotape, transmisisatelite atau computer ( Tafiardi: 2005 ).

E-Learning merupakan segala teknologi yang digunakan untuk mendukung usaha- usaha pengajaran lewat teknologi elektronik internet. Internet, satelit, tape audio/ vidio, Tv interaktif, dan CD ROM adalah sebagian dari media elektronik yang digunakan (Onno W.Purbo dalam Amin : 2004 ).

Dari berbagai macam defenisi dapat disimpulkan bahwa yang disebut sebagai E-learning adalah konsep pendidikan yang 
memamfaatkan teknologi informasi dan komunikasi dalam proses belajar mengajar.

Pembelajaran dengan

menggunakan e-learning terbagi menjadi tiga jenis, yaitu:

\section{Teks dan Grafik Web based Learning}

Teks dan Grafik adalah bentuk yang paling sederhana dalam web based training program. Instruktur hanya menyimpan materi-materi kursus atau pelatihannya didalam $w e b$, dan murid dapat mengaksesnya dengan mudah. Karena hanya menampilkan teks dan grafik saja, level interaktifitas dari model web elearning seperti ini sangat rendah.

\section{Interactive Web based Learning \\ Model web e-learning seperti} ini memiliki level interaktifitas yang lebih tinggi dibanding model yang pertama. Biasanya model ini dilengkapi dengan sarana-sarana latihan atau self-test, text entry, column matching, dan lain-lain.

\section{Interactive Multimedia Web based Learning.}

Kebanyakan program pelatihan atau belajar dengan menggunakan model seperti ini biasanya bisa membuat interaksi antara guru dan murid secara real-time / synchronous melalui audio dan video streaming, interactive web discussion, bahkan audio/video desktop conference. Level interaktifitas model ketiga ini paling tinggi diantara yang lainnya dan paling rumit dalam pelaksanaannya, tetapi model ini diharapkan dapat mencakup semua kondisi belajar-mengajar pada kelas tatap muka.

\section{Decision Support Framework}

Pengertian sistem pendukung keputusan yang dikemukakan oleh Michael S Scott Morton dan Peter G W Keen, dalam buku Sistem Informasi Manajemen (McLeod, 1998) menyatakan bahwa sistem pendukung keputusan merupakan sistem penghasil informasi yang ditujukan pada suatu masalah yang harus dibuat oleh manajer.

Menurut Raymond McLeod, Jr (1998) mendefinisikan sistem pendukung keputusan merupakan suatu sistem informasi yang ditujukan untuk membantu manajemen dalam memecahkan masalah yang dihadapinya. Definisi selengkapnya adalah sistem penghasil informasi spesifik yang ditujukan untuk memecahkan suatu masalah tertentu yang harus dipecahkan oleh manajer pada berbagai tingkatan.

Definisi menurut Litlle mengemukakan bahwa sistem pendukung keputusan adalah suatu sistem informasi berbasis komputer yang menghasilkan berbagai alternatif keputusan untuk membantu manajemen dalam menangani berbagai permasalahan yang terstruktur ataupun tidak terstruktur dengan menggunakan data atau model.

\section{Komponen sistem pendukung keputusan \\ Secara garis besar Decision} Support System (DSS) atau Sistem Pendukung Pengambilan Keputusan dibangun oleh tiga komponen besar:

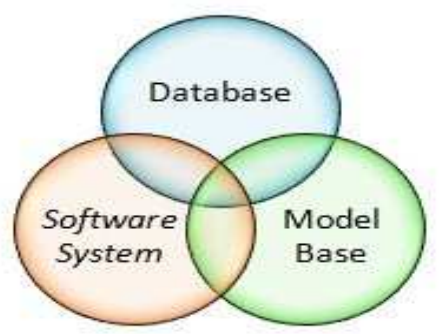


Gambar 1. Komponen SPK

\section{Sistem DataBase}

Sistem database berisi kumpulan dari semua data bisnis yang dimiliki perusahaan atau lembaga, baik yang berasal dari transaksi sehari-hari, maupun data dasar (master file). Untuk keperluan DSS, diperlukan data yang relevan dengan permasalahan yang hendak dipecahkan melalui simulasi.

\section{Model Base}

Model Base atau suatu model yang merepresentasikan permasalahan ke dalam format kuantitatif (model matematika sebagai contohnya) sebagai dasar simulasi atau pengambilan keputusan, termasuk di dalamnya tujuan dari permasalahan (obyektif), komponen-komponen terkait, batasan-batasan yang ada (constraints), dan hal-hal terkait lainnya.

\section{Software System}

Kedua komponen tersebut untuk selanjutnya disatukan dalam komponen ketiga yaitu software system, setelah sebelumnya direpresentasikan dalam bentuk model yang "dimengerti" komputer. Contohnya adalah penggunaan teknik RDBMS (Relational Database Management System), OODBMS (Object Oriented Database Management System) untuk memodelkan struktur data. Sedangkan MBMS (Model Base Management System) dipergunakan untuk mere-presentasikan masalah yang ingin dicari pemecahannya. Entiti lain yang terdapat pada produk DSS baru adalah DGMS (Dialog Generation and Management System), yang merupakan suatu sistem untuk memungkinkan terjadinya "dialog" interaktif antara komputer dan manusia sebagai pengambil keputusan.

\section{Beberapa Fase dalam Proses Pengambilan Keputusan}

Dalam proses pengmabilan keputusan ada empat macam fase yang harus dilalui, fase tersebut antara lain :

\section{Fase inteligensi}

Intelegensi dalam pengambilan keputusan meliputi pemindahan (scanning) lingkungan intelegensi mencakup berbagai aktifitas yang menekankan identifikasi situasi atau peluang- peluang masalah Fase inteligensi dimulai dengan identifikasi terhadap tujuan dan sasaran organisasional yang berkaitan dengan isu yang terkait dan menentukan apakah tujuan telah terpenuhi.

\section{Fase Desain}

Fase desain meliputi penemuan atau mengembangkan dan menganalisis tindakan yang mungkin dilakukan sebuah model masalah pengambilan keputusan dibangun dites dan divalidasi permodelan meliputi konseptualisasi masalah dan mengabstraksikan masalah ke dalam bentuk kuantitatif dan kualitatif.

\section{Fase Pilihan}

Fase pilihan adalah fase dimana dibuat suatu keputusan yang nyata dan diambil suatu komitmen untuk mengikuti tindakan tertentu.

\section{Fase Implementasi}

Fase Implementasi meliputi membuat suatu solusi yang direkomendasikan bisa berkerja bagan pada proses pengambilan keputusan. 


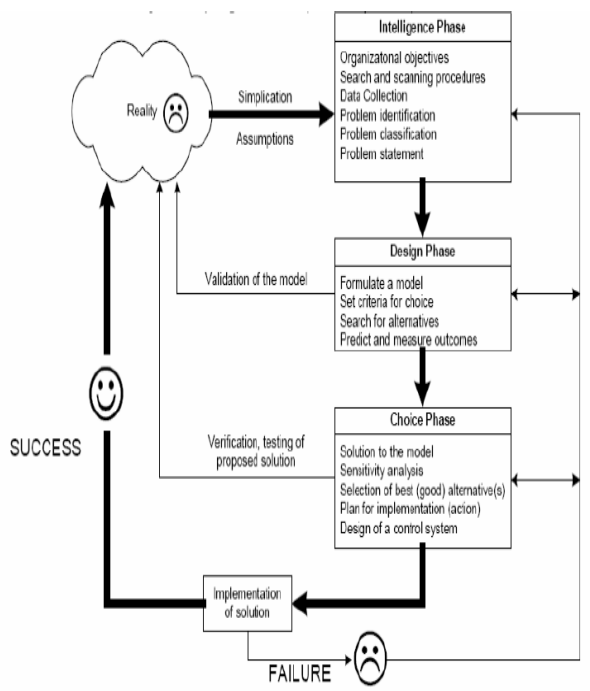

Gambar 2. Bagan proses pengambilan keputusan

Metode Analytic Network Process (ANP)

Metode Analytic Network Process (ANP) merupakan pengembangan metode Analytical Hierarchy Process (AHP). Metode ANP mampu memperbaiki kelemahan AHP berupa kemampuan mengakomodasi keterkaitan antar kriteria atau alternatif. Keterkaitan pada metode ANP ada 2 jenis yaitu keterkaitan dalam satu set elemen (inner dependence) dan keterkaitan antar elemen yang berbeda (outer dependence). Adanya keterkaitan tersebut menyebabkan metode ANP lebih kompleks dibandingkan dengan metode AHP.
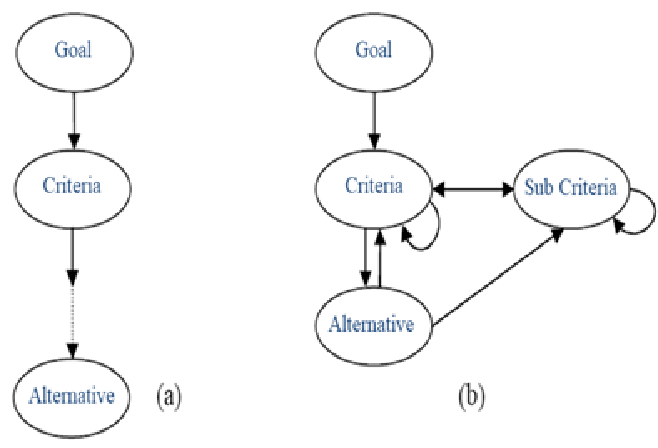

(b)
Gambar 3. (a) Struktur AHP, (b) Struktur ANP (Chung et. al., 2006)

Langkah-langkah Metode Analytic Network Process (ANP)

Secara umum langkah-langkah yang harus dilakukan dalam menggunakan ANP adalah sebagai berikut (Saaty, 1991) :

1. Mendefinisikan masalah dan menentukan kriteria solusi yang diinginkan.

2. Menentukan pembobotan komponen dari sudut pandang manajerial.

3. Membuat matriks perbandingan berpasangan yang menggambarkan kontribusi atau pengaruh setiap elemen atas setiap kriteria. Perbandingan dilakukan berdasarkan penilaian dari pengambil keputusan dengan menilai tingkat kepentingan suatu elemen.

4. Setelah mengumpulkan semua data perbandingan berpasangan dan memasukkan nilai-nilai kebalikannya serta nilai satu di sepanjang diagonal utama, prioritas masing-masing kriteria dicari dan konsistensi diuji.

5. Menentukan eigenvector dari matriks yang telah dibuat pada langkah ketiga.

6. Mengulangi langkah 3, 4, dan 5 untuk semua kriteria.

7. Membuat unweighted super matrix dengan cara memasukkan semua eigen vector yang telah dihitung pada langkah 5 ke dalam sebuah super matriks.

8. Membuat weighted super matrix dengan cara melakukan 
perkalian setiap isi unweighted supermatrix terhadap matriks perbandingan kriteria (cluster matrix).

9. Membuat limiting supermatrix dengan cara memangkatkan super matriks secara terus menerus hingga angka disetiap kolom dalam satu baris sama besar, setelah itu lakukan normalisasi terhadap limiting supermatrix.

10. Ambil nilai dari alternatif yang dibandingkan kemudian dinormalisasi untuk mengetahui hasil akhir perhitungan.

11. Memeriksa konsistensi, rasio konsistensi tersebut harus 10 persen atau kurang. Jika nilainya lebih dari $10 \%$, maka penilaian data keputusan harus diperbaiki.

\section{Penyusunan Prioritas}

Menyusun prioritas merupakan salah satu bagian yang penting dan perlu ketelitian di dalamnya. Pada bagian ini ditentukan skala kepentingan suatu elemen terhadap elemen lainnya. Langkah pertama dalam penyusunan prioritas adalah menyusun perbandingan berpasangan, yaitu membandingkan dalam bentuk berpasangan seluruh untuk setiap sub sistem hirarki. Perbandingan tersebut kemudian ditransformasikan ke dalam bentuk matriks untuk maksud analisis numerik, yaitu matriks $\mathrm{n} \times \mathrm{n}$.

Misalkan terdapat suatu sub sistem hirarki dengan kriteria $A$ dan sejumlah elemen di bawahnya, $B_{1}$ sampai Bn. Perbandingan antar elemen untuk sub sistem hirarki itu dapat dibuat dalam bentuk matriks $\mathrm{n} x$ n. Matriks ini disebut matriks perbandingan berpasangan.
Tabel 1. Matriks Perbandingan Berpasangan

\begin{tabular}{|c|ccc|}
\hline $\mathrm{A}$ & $\mathrm{B}_{1}$ & $\mathrm{~B}_{2}$ & $\mathrm{~B}_{3}$ \\
$\mathrm{~B}_{1}$ & $\mathrm{~B}_{11}$ & $\mathrm{~B}_{12}$ & $\mathrm{~B}_{13}$ \\
$\mathrm{~B}_{2}$ & $\mathrm{~B}_{21}$ & $\mathrm{~B}_{22}$ & $\mathrm{~B}_{23}$ \\
$\mathrm{~B}_{3}$ & $\mathrm{~B}_{31}$ & $\mathrm{~B}_{32}$ & $\mathrm{~B}_{33}$ \\
--- & --- & -- & \\
$\mathrm{B}_{\mathrm{n}}$ & & -- & \\
& $\mathrm{B}_{\mathrm{n} 1}$ & $\mathrm{~B}_{\mathrm{n} 2}$ & $\mathrm{~B}_{\mathrm{n} 3}$ \\
\hline
\end{tabular}

\section{Berdasarkan Tabel 2.1, kita dapat menentukan skala perbandingan antar elemen dalam proses pengambilan keputusan.}

Tabel 2. Tabel Penilaian Perbandingan Berpasangan

\begin{tabular}{|c|c|c|}
\hline $\begin{array}{l}\text { Tingkat } \\
\text { Kepen- } \\
\text { tingan }\end{array}$ & Definisi & Keterangan \\
\hline 1 & $\begin{array}{c}\text { Sama } \\
\text { Penting }\end{array}$ & $\begin{array}{lr}\text { Kedua } & \text { elemen } \\
\text { mempunyai } & \text { pengaruh } \\
\text { yang sama } & \\
\end{array}$ \\
\hline 3 & $\begin{array}{l}\text { Sedikit } \\
\text { Lebih } \\
\text { Penting }\end{array}$ & $\begin{array}{l}\text { Pengalaman dan } \\
\text { penilaian sedikit } \\
\text { memihak satu elemen } \\
\text { dibandingkan } \\
\text { pasangannya }\end{array}$ \\
\hline 5 & $\begin{array}{l}\text { Lebih } \\
\text { Penting }\end{array}$ & $\begin{array}{l}\text { Pengalaman dan } \\
\text { penilaian dengan kuat } \\
\text { memihak satu elemen } \\
\text { dibandingkan } \\
\text { pasangannya }\end{array}$ \\
\hline 7 & $\begin{array}{l}\text { Sangat } \\
\text { Penting }\end{array}$ & $\begin{array}{l}\text { Satu elemen sangat } \\
\text { disukai dan secara } \\
\text { praktis dominasinya } \\
\text { terlihat }\end{array}$ \\
\hline 9 & $\begin{array}{l}\text { Mutlak } \\
\text { Sangat } \\
\text { Penting }\end{array}$ & $\begin{array}{ll}\text { Satu elemen } & \text { terbukti } \\
\text { mutlak lebih } & \text { disukai } \\
\text { dibandingkan } & \\
\text { pasangannya } & \end{array}$ \\
\hline $2,4,6,8$ & $\begin{array}{c}\text { Nilai } \\
\text { Tengah }\end{array}$ & $\begin{array}{l}\text { Ketika diperlukan } \\
\text { sebuah kompromi }\end{array}$ \\
\hline
\end{tabular}




\section{Pengujian Konsistensi Matriks Perbandingan \\ Pembobotan dengan ANP
membutuhkan model yang} merepresentasikan saling keterkaitan antar kriteria dan subkriteria yang dimilikinya. Ada 2 kontrol yang perlu diperhatikan di dalam memodelkan sistem yang hendak diketahui bobotnya. Kontrol pertama adalah kontrol hierarki yang menunjukkan keterkaitan kriteria dan sub kriterianya. Pada kontrol ini tidak membutuhkan struktur hierarki seperti pada metode AHP. Kontrol lainnya adalah kontrol keterkaitan yang menunjukkan adanya saling keterkaitan antar kriteria atau cluster (Saaty, 1996).

Jika diasumsikan suatu sistem memiliki $N$ cluster di mana elemenelemen dalam tiap cluster saling berinteraksi atau memiliki pengaruh terhadap beberapa atau seluruh cluster yang ada. Jika cluster dinotasikan dengan $C h$, di mana $h=1$, $2, \ldots, N$, dengan elemen sebanyak $n h$ yang dinotasikan dengan eh1, eh2, ..., ehnh. Pengaruh dari satu set elemen dalam suatu cluster pada elemen yang lain dalam suatu sistem dapat direpresentasikan melalui vektor prioritas berskala rasio yang diambil dari perbandingan berpasangan.

Jaringan pada metode ini memiliki kompleksitas yang tinggi dibanding dengan jenis lain, karena adanya fenomena feedback dari cluster satu ke cluster lain, bahkan dengan cluster-nya sendiri. Pada Gambar 2.8, memperlihatkan model jaringan dengan feedback dan dependence cluster satu dengan cluster lainnya.

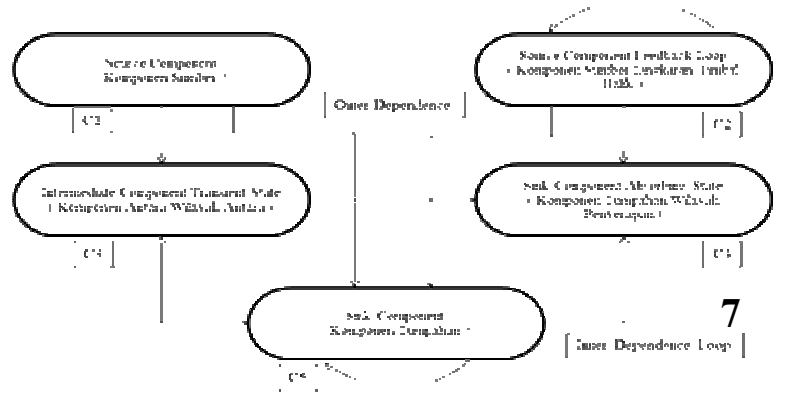

\section{Gambar 4. Model Feedback dan Dependence pada Cluster}

Pada Gambar 4, terdapat 5 klaster yaitu C1, C2, C3, C4 dan C5. C1 dan C2 tidak ada panah yang menuju ke arahnya maka disebut komponen sumber. Pada C3 dan C4 ada anak panah yang keluar dan menuju kearahnya maka disebut komponen transien. Selain itu, C3 dan C5 terdapat panah bolak balik maka dikatakan terdapat siklus antara C3 dan C5. Pada C2 dan C5 terdapat panah yang menghubungkan dengan dirinya sendiri, hal tersebut disebut inner dependence loop. Hubungan lain bisa terlihat antara C1dan C5, C2 dan C5, atau C4 dan C5 disebut sebagai outer dependence.

Setelah model dibuat, maka dilakukan pentabelan dari hasil data pairwise comparison dengan menggunakan tabel supermatriks. Kemudian akan dilakukan proses pembobotan untuk setiap cluster yang telah ditentukan berdasarkan kriteria calon pengurus. Algoritma perhitungan pembobotan yang dilakukan dimulai dari data dengan bentuk pairwaise comparison sampai dihasilkan bobot tiap indikator kinerjanya. Kriteria dibuat berdasarkan kebutuhan dan tujuan dari pemilihan.

Untuk menunjukkan hasil akhir dari perhitungan perbandingan maka supermatriks akan dipangkatkan secara terus-menerus hingga angka setiap kolom dalam satu baris sama besar.

\section{Teknik Analisa Data}

Analisis yang digunakan dalam penelitihan ini adalah analisis 
deskriptif dan Analytical Network Process ( ANP ). Analisis deskriptif dilakukan melalui penyajian rangkuman hasil survey dan identifikasi dalam bentuk tabulasi / grafik.dengan analisis ini akan digambarkan kondisi pengambilan keputusan di SMP NEGERI 24 PADANG. Pada saat ini sedangkan ANP digunakan sebagai instrument untuk menentukan pioritas mentode pembelajaran mengunakan e-learning.

\section{Analisis, Dan Implementasi}

Dalam penelitihan ini penulis melakukan pengumpulan data dengan mengunakan kuesioner untuk memudahkan proses perbandingan antara kriteria dan alternative. Hasil dari kuesioner ini dirata-rata dan nilai rata-rata tersebut menjadi nilai dasar dari perbandingan kriteria dan alternatif yang terdapat dalam sistem. Nilai rata-rata perbandingan tersebut dihitung dengan menggunakan metode Analytic Network Process (ANP) untuk mendapatkan bobot akhir masing-masing kriteria dan alternatif. Pada proses survei ini, pihak yang mengisi kuesioner adalah siswa dan guru.

\section{Data Alternatif}

Data alternatif diambil dari data sistem e-learning. Berdasarkan sistem tersebut, ada 3 sistem sebagai perbandingan dalam pengujian. Dan untuk hasil perbandingan beberapa node dalam Fasilitas. Node yang dimaksud adalah : Guru, siswa dan tempat belajar.

Metode ANP Berikut adalah gambar metode ANP dalam penentuan sistem e-learning melalui software SuperDecision:

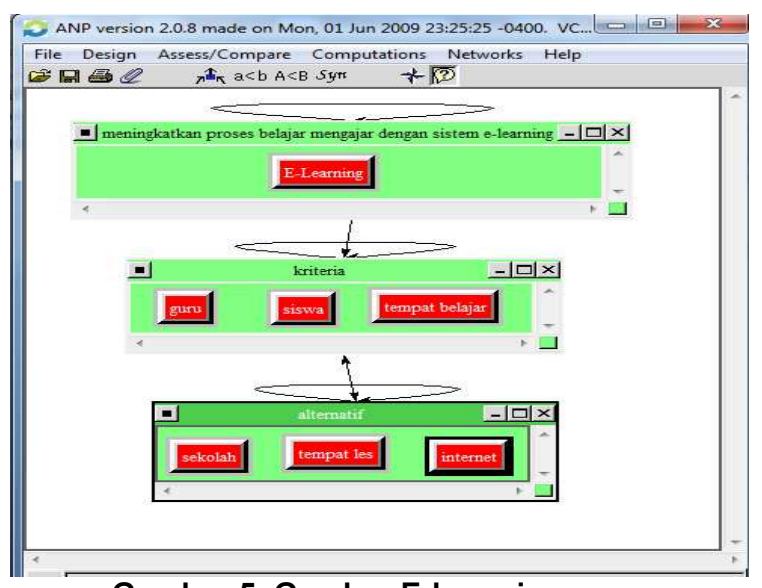

Gambar 5. Gambar E-Learning

Dalam studi kasus ini untuk meningkatkan proses pembelajaran dengan mengunakan sistem $e$ learning sebagai pemilihan media pembelajaran yang digunakan didalam proses belajar yang tepat, dimana didalam penentuan sistem $e-$ learning berupa element alternative berupa: sekolah, tempat les, dan internet dimana adanya beberapa kriteria sebagai claster dimana kriteriannya terdiri dari: guru siswa dan tempat belajar.

Perbandingan dalam cluster dan Perbandingan antar cluster didapat dari kuesioner yang disebar ke responden. Berikut adalah gambar perbandingan antar alternative dalam kriteria dan perbandingan antar kriteria yang didapat dari kuesioner :

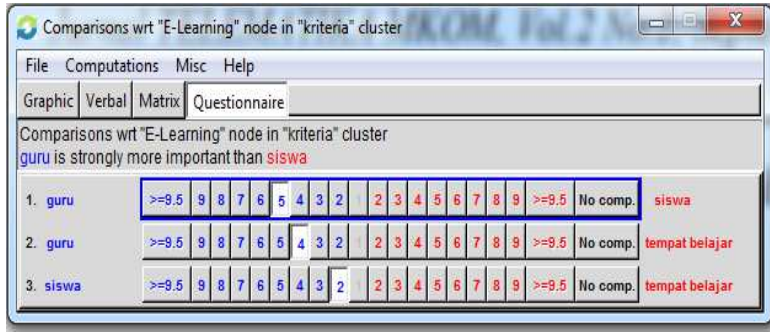

Gambar 6. Perbandingan Antar Alternative Dalam Cluster 


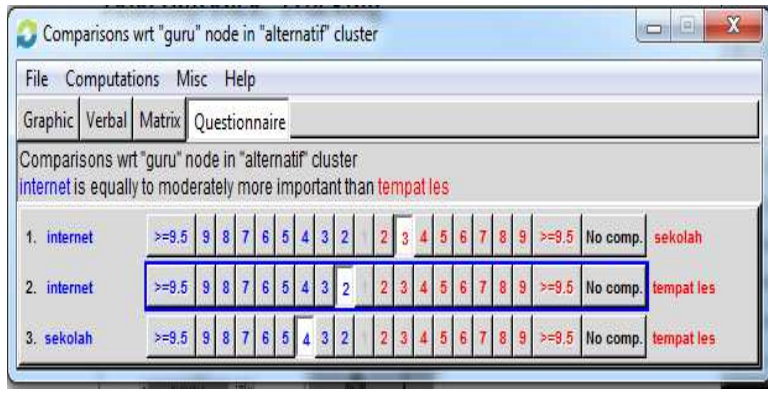

Gambar 7. Perbandingan Node Dalam Cluster

Hasil Penelitian Dalam penelitian ini, digunakan metode ANP dengan bantuan software Superdecision untuk mentukan sistem e-learning. Alternatif :

1. Sistem e-learning dengan mengunakan sekolah.

2. Sistem e-learning mengunakan internet

3. Sietem e-learning mengunakan tempat les

Hasil penelitihan dari masing masing cluster :

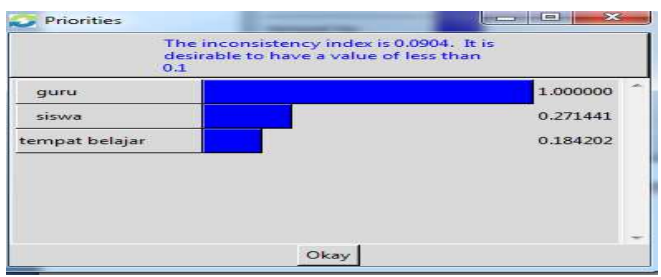

Gambar 8. Hasil Perbandingan Antar Alternative Dalam Cluster

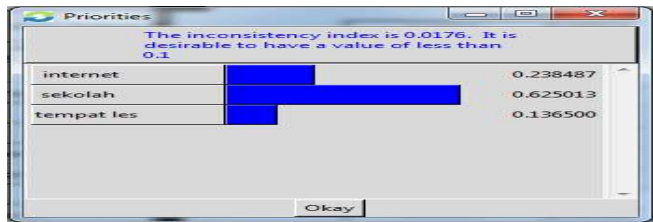

Gambar 9. Hasil Perbandingan Node Dalam Cluster.

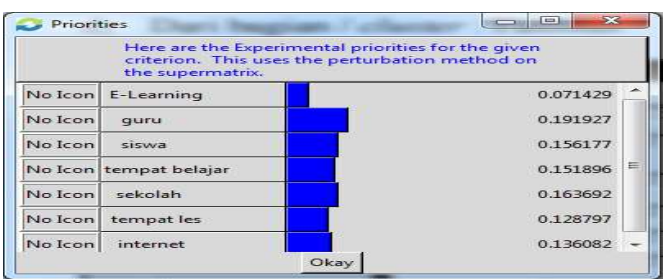

Gambar 10. Hasil Penelitian Prioritas Node Sistem E-Learning Dalam Cluster Fasilitas
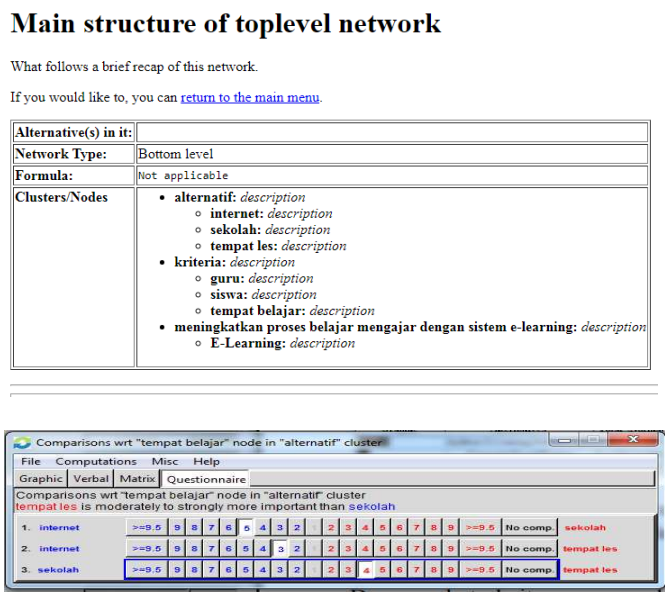

Gambar 11. Perbandingan Cluster Fasilitas Dalam ANP

Data tersebut diolah melalui software Super Decision maka akan dihasilkan:

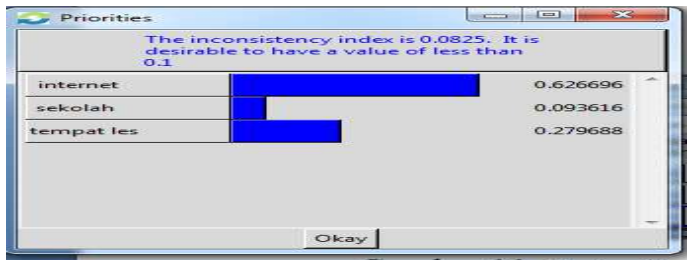

Gambar 12. Hasil Penelitian Prioritas Sistem E-Learning Antar Semua Cluster

\section{KESIMPULAN}

Dari penelitian yang dilakukan pada sistem e-learning, maka didapatkan: a) Cluster-cluster yang menentukan sistem e-learning. Berdasarkan hasil interview atau wawancara dan kuesioner, maka Fasilitas menentukan 3 node terbesar untuk menentukan sistem e-learning. 
Dan berdasarkan hasil pengujian yang dilakukan pada metode ANP dengan software SuperDecision maka didapatkan: bahwa sistem pembelajaran yang paling mendukung selain adanya peranan guru sebagai pengajar, baik sekolah namun factor utama yang saat ini mendukung adalah internet, sekolah dan tempat les.

\section{DAFTAR PUSTAKA}

[1] Hendy Hendharto. 2008. Analytic Network Process (ANP) Method For Multi Purpose Research. Lokakarya. Jakarta.

[2] Turban, Efraim, Jay E. Aronson, Ting Peng Liang. 2005. Decision Support Systems and Intelligent Systems", 7th edition. PrenticeHall. New Jersey.

[3] Seok, Soonhwa. 2008. The aspect of elearning. International Journal on ELearning, Proquest, 7(4), 725-741.

[4] Siahaan, Sudirman. 2004. ELearning (Pembelajaran Elektronik) Sebagai Salah Satu Alternatif Kegiatan Pembelajaran. Sumber dari internet.

[5] E-learning Onno W.Purbo dalam Amin : 2004 